\title{
Nevşehir’de Baykuş Peletlerindeki Memeli Hayvan Kalıntılarının Dağılımı
}

\author{
Alaettin Kaya $^{1, *}$, Yüksel Coşkun ${ }^{1}$ \\ ${ }^{1}$ Dicle Üniversitesi Fen Fakültesi Biyoloji Bölümü-Diyarbakır
}

Özet

Bu çalışmada Eylül-2010'da Nevşehir ili Devlet Hastanesi civarındaki ağaçların diplerinden Athene noctua, Tyto alba ve Bubo bubo türlerine ait 96 pelet toplanmış ve içerikleri incelenmiştir. 96 pelet içerisinde toplam 246 adet memeli kalıntısı bulunmuştur. Genel olarak her pelette bir veya üç hayvan kalıntısı bulunurken, maksimum altı (ortalama 2.2) hayvan kalıntısına rastlanmıştır. Peletlerde Soricimorpha'dan Crocidura suaveolens ve Rodentia takımından Microtus guentheri, Microtus socialis, Microtus sp., Mus macedonicus, Mus musculus, Mus sp., Cricetulus migratorius, Meriones tristrami, Apodemus sylvaticus'a ait kalıntılar tespit edilmiştir. Memelilerin büyük kısmını \%99.6 oranı ile Rodentia ordosu; bunların çoğunluğunu da Microtinae türlerinin (\%79.7) oluşturduğu gözlenmiştir. Microtus guentheri \%46.7 oran ile kalıntılarda baskın olurken Microtus socialis \%23.2 oranı ile en sık görülen ikinci, Microtus sp. \%9.8 oranı ile sık bulunan üçüncü tür olmuştur. Meriones tristrami ile Apodemus sylvaticus kalıntılarda birbirlerine eşit (\%7.3) oranda bulunurken, Crocidura suaveolens (\%0.4) kalıntılar içinde en az yoğunlukta tespit edilen tür olmuştur. Bunların dışında kuş (\%4) böcek (\%2) ve bir adet sürüngen kalıntısı da bulunmuştur.

Anahtar Kelimeler: Mammalia, Soricimorpha, Rodentia, Baykuş Peleti, Nevşehir.

\section{The Remains of Mammals in the Owl Pellets from Nevşehir Province}

\begin{abstract}
In this study in total 96 pellets that belongs to species of Athene noctua, Tyto alba and Bubo bubo were collected from under the tree near State Hospital of Nevşehir city and remains were analyzed. Maximum six (in average 2.2) animal remains were found in each pellet, while one or tree animal remains were found generally. Crocidura suaveolens belong to Soricimorpha and Microtus guentheri, Microtus socialis, Microtus sp., Mus macedonicus, Mus musculus, Mus sp., Cricetulus migratorius, Meriones tristrami, Apodemus sylvaticus belong to order Rodentia, in total 246 mammal remains were identified. The Rodentia order was the mostly found with a ratio of $99.6 \%$ in mammal remains. It was observed that the majority of these were consisted by Microtinae species (79.7\%). Microtus guentheri was the predominant species with a ratio of $46.7 \%$, the second most common species was Microtus socialis with a ratio of $23.2 \%$, the third most common species was Microtus sp. with a ratio of $9.78 \%$ in remains. Crocidura suaveolens was least common species with a ratio of $0.4 \%$ in remains, as Meriones tristrami and Apodemus sylvaticus's ratio (7.3\%) were equal. Additionally, birds (4\%), insects (2\%) and one reptilian remains were found.
\end{abstract}

Keywords: Mammalia, Soricimorpha, Rodentia, Owl Pellets, Nevşehir.

\section{Giriş}

"e-mail: altkaya @ dicle.edu.tr 
Baykuşların bütün olarak ya da iri parçalar halinde yuttukları, küçük memeli, kuş, sürüngen ve böcek gibi besinlerindeki sindiremedikleri kafatası, diş, kemik, kıl, tüy ve post içeren, genellikle gri renkli kusmuk topaklarına pelet adı verilir. Baykuş pelet içeriğinin analizi, küçük memeli hayvan faunasının ortaya çıkarılması çalışmalarında geleneksel yöntemlere ilave olarak uzun zamandan beri kullanılmaktadır. Bu yöntem özellikle nadir görülen ve özel habitatlara veya farklı davranışlara sahip türlerin tespit edilmesinde önem taşımaktadır.

Memeli türlerinin tespitinde baykuşlara ait pelet analiz çalışmaları son yıllarda yaygın olarak kullanılmaktadır [1-4]. Türkiye'de bu çalışmalar sınırlı sayıdadır. Beyşehir Gölü çevresinden Asio otus [5]; Antakya çevresinden Tyto alba [6]; Sultan sazlı̆̆ından ve Bafa gölü’nden [7 ve 8]; Bitlis'ten Bubo bubo [9]; Bursa çevresinden Strix aluco [10]; Adana-Toprakkale çevresinden alınan peletleri [11] incelemişlerdir. Diyarbakır çevresinden Asio otus peletlerini [12] incelemiş ve bu peletlerde 8 memeli hayvan türüne ait kalıntılar tespit etmişlerdir. İç Anadolu'dan, Asio otus [13-15]; Kilis ve Şanlıurfa'dan Athene noctua ve Tyto alba 'ya ait peletlerde [16] analiz yapmışlar ve çeşitli memeli türlerine ait kalıntılar tespit etmişlerdir.

Bu çalışmada, Nevşehir ilinden Athene noctua (Kukumav), Tyto alba (Peçeli baykuş) ve Bubo bubo (Puhu)'ya ait peletlerin analizi ile Nevşehir çevresindeki küçük memelilerin dağılımları ve yoğunlukları hakkında bilgi edinilmesi amaçlanmıştır.

\section{Materyal ve Metot}

Bu çalışmada 2010 yılının Eylül ayında Athene noctua, Tyto alba ve Bubo bubo türlerine ait 96 pelet örneği, Nevşehir Devlet Hastanesi civarındaki ( $38^{\circ} 39^{\prime} \mathrm{K}$ ve $\left.34^{\circ} 43^{\prime} \mathrm{D}\right)$ ağaçların diplerinden toplanmıştır. Kalıntılar Dicle Üniversitesi Fen Fakültesi Biyoloji Bölümü’nde korunmaktadır.

Pelet analizleri standart yöntemlere [1 ve 2] uygun olarak yapılmıştır. Sterilizasyon amacıyla her pelet önce birkaç dakika \% 70'lik etil alkol içinde bekletilmiştir. Daha sonra pelet su içine alınarak iyice yumuşaması sağlanmış, ardından her pelet iğne ve pens yardımı ile didiklenerek açılmıştır. Her pelet içeriği; kafatası, alt çene ve diğer kemikler analiz için ayrı kutulara alınmıştır. Kalıntıların hangi türlere ait olduğunu ayırt etmek için [17 -22]'nin tür tayin anahtarları kullanılmıştır.

\section{Bulgular}

Elde edilen 96 pelet içerisinde 246 memeli hayvan kalıntısı ayırt edilmiştir. Pelet içeriklerinin büyük kısmını küçük memeli hayvanların oluşturduğu görülmüştür. Genel olarak her pelette 1-3 hayvan kalıntısı bulunurken, maksimum altı (ortalama 2.2) hayvan kalıntısına rastlanmıştır. Toplanan peletlerden yirmi bir tanesinde bir; elli iki tanesinde iki; on dört tanesinde üç; altı tanesinde dört; bir tanesinde beş; iki tanesinde altı adet hayvan kalıntısı (1 adet Apodemus sylvaticus, 4 adet Mus macedonicus, 1 adet Microtus guentheri) bulunmuştur. İki memeli ordosundan yedi türe (Soricimorpha: Crocidura suaveolens, ve Rodentia: Microtus guentheri, Microtus socialis, Microtus sp., Mus macedonicus, Mus musculus, Mus sp., Cricetulus migratorius, Meriones tristrami, Apodemus sylvaticus) ait kalıntılar tespit edilmiştir (Şekil 1).

Memeli kalıntılarının \%99.6'sını Rodentia ordosu; (kemirgenler) bunların da \%79.7 oranı ile çoğunluğunu Microtinae türleri oluşturmaktadır. M. guentheri \%46.7 oran ile kalıntılarda baskın olurken 
(Şekil 1), M. socialis \%23.2 oranı ile en s1k görülen ikinci, Microtus sp. \%9.8 oranı ile sık bulunan üçüncü tür olmuştur. M. tristrami ile A. sylvaticus kalıntılarda birbirlerine eşit (\%7.3) oranda bulunurken, C. suaveolens (\%0.4) kalıntılar içinde en az yoğunlukta tespit edilen tür olmuştur. Ayrıca, kuş (\%4) böcek (\%2) ve bir adet sürüngen kalıntısı da bulunmuştur.

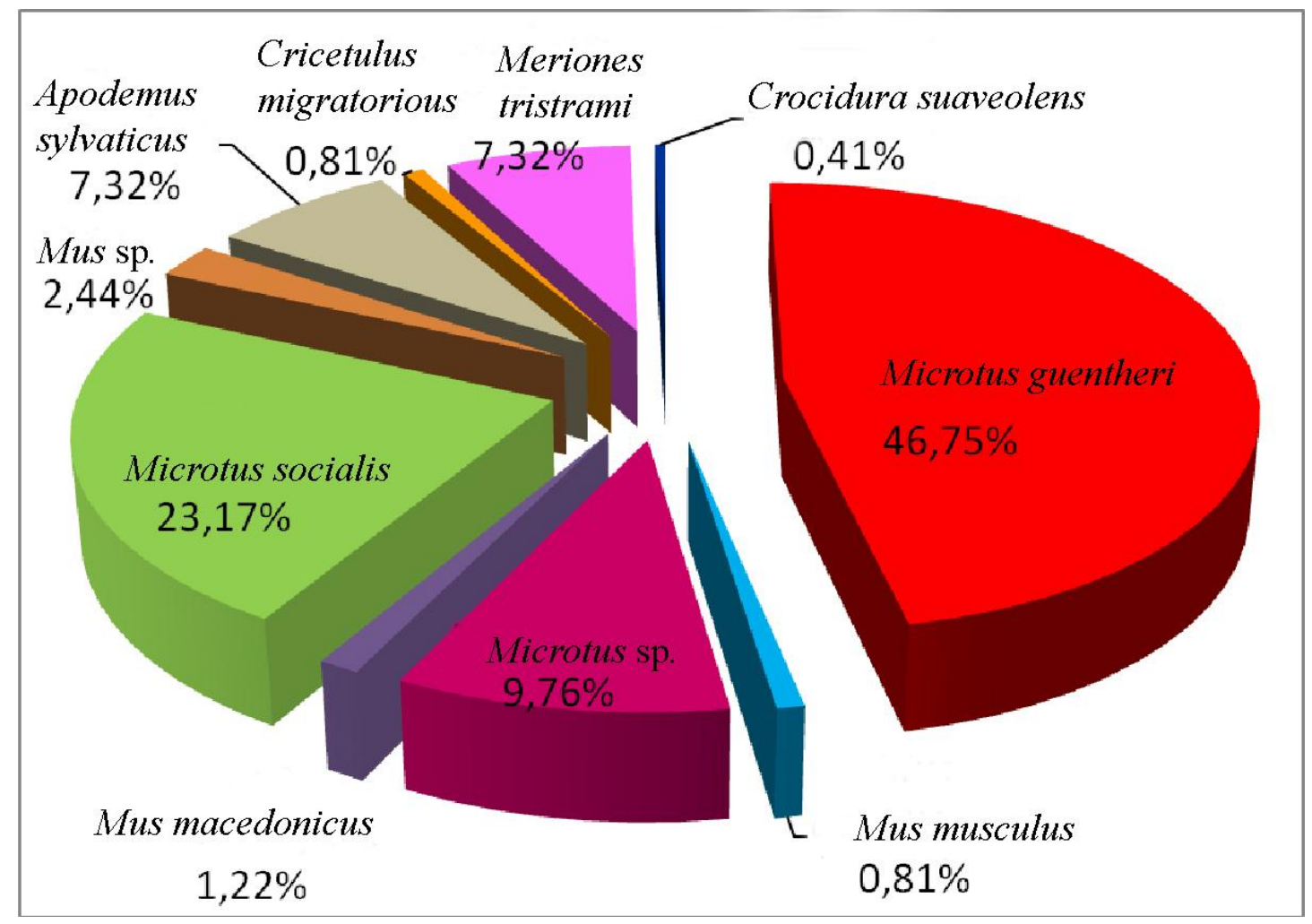

Şekil 1- Kalıntılardaki memeli türlerinin oransal dağılımı.

\section{Tartışma ve Sonuç}

Diyarbakır'dan Asio otus peletlerinde, her pelette genel olarak bir veya iki; bir pelette maksimum dört memeli hayvan kalıntısı bulunmuştur [12 ve 23]. Bu çalışmada bir pelette maksimum altı kalıntıya rastlanmıştır. Baykuşların avlarının \%93-99'unu kemirgenlerin, özellikle tarla farelerinin oluşturduğunu; Ürdün'de sıklıkla görülen tür M. musculus/abboti iken, Irak ve Türkiye'de dominant türün $M$. tristrami olduğunu ifade etmişlerdir [24]. Güneydoğu Anadolu Bölgesi’nden çeşitli baykuşlara ait peletlerde memeliler içinde rodent'lerin \%94.5 oranıla en fazla rastlanan grup olduğunu; Microtin'ler ve Murid'lerin insan aktivitelerinden çok etkilenmedikleri için pelet kalıntıları içinde yoğun olarak tespit edildiğini; boylarının küçüklüğü dolayısıyla tuzakla yakalanmaları zor olan $C$. suaveolens ve $M$. macedonicus türlerine de peletlerde sıklıkla rastlandığını kaydetmiştir [25]. Nevşehir'de toplanan peletler içerisinde memelilerin çoğunluğunu Microtin ve Murid türleri oluşturmaktadır.

Asio otus peletlerinde tespit ettikleri 8 memeli hayvan türü içinde M. guentheri’nin en fazla orana (\%71.3) sahip olduğunu, bu türü M. musculus'un \%19.6' lık oranla takip ettiğini kaydetmişlerdir [12]. Kalıntılarda C. suaveolens ve Allactaga williamsi, Cricetulus migratorius, M. tristrami, Mescocricetus brandti, M. guentheri ve M. macedonicus bulunduğunu tespit etmiş ve ağırlıklı olarak 
Rodentia örneklerinin (\%93.8) olduğunu bildirmiştir [13]. M. guentheri, Apodemus flavicollis, M. macedonicus, M. levis, Rattus norvegicus, C. suavolens, Nannospalax nehringi ve C. migratorius örneklerini tespit etmiş ve Rodentia örneklerinin kalıntıların \%97.2'sini temsil ettiğini ifade etmişlerdir [14]. M. guentheri, M. levis, A. sylvaticus, A. flavicollis, M. tristrami, M. auratus, Cricetus cricetus, M. musculus, Rattus rattus, R. norvegicus, M. macedonicus, N. nehringi ve C. suaveolens türlerini tespit etmiş ve kalıntıların \%50'sini M. guentheri ve M. levis'in oluşturduğunu bildirmişlerdir [15] (Tablo 1). Şanlıurfa ve Kilis'ten C. suaveolens, Suncus etruscus, C. migratorius, M. auratus, Gerbillus dasyurus, M. tristrami, M. cf. irani, M. socialis, M. guentheri, M. macedonicus, Apodemus sp., N. ehrenbergi ve Dryomys nitedula türlerini tespit etmiş ve Rodentia türlerinin kalıntıların \%89.2'sini temsil ettiğini ifade etmiştir [16].

Tablo 1. Bölgede yapılan pelet çalışmalarında tespit edilen memeli türleri ve diğer kalıntılar (+: var, -: yok).

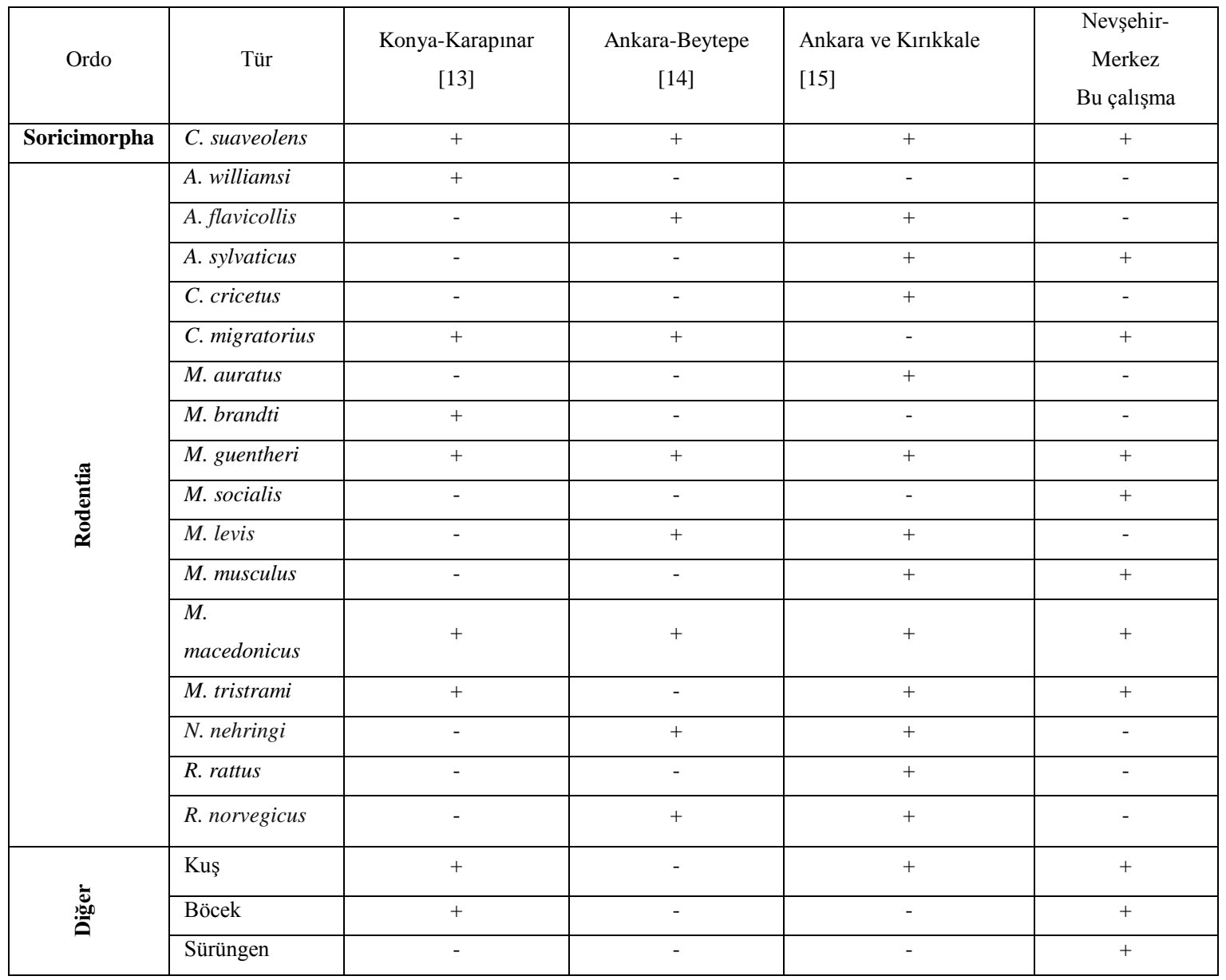

İç Anadolu bölgesinde A. williamsi ve M. brandti [13]; A. flavicollis, M. levis, R. norvegicus ve N. nehringi [14]; N. nehringi, A. flavicollis, M. auratus, C. cricetus, M. musculus, R. rattus, R. norvegicus ve M. levis [15]; Kilis ve Şanlıurfa illerinde, S. etruscus, M. auratus, G. dasyurus, M. cf. irani, M. socialis, N. ehrenbergi ve D. nitedula [16] türlerini bildirmişlerdir. Ancak, bu araştırıcıların peletlerde bulunduğunu bildirdikleri bu türlerin kalıntılarına Nevşehir yöresinde elde ettiğimiz peletler içerisinde rastlanmamıştır. Ayrıca, Nevşehir'de Rodentia oranı yukarıda verilen çalışmalardan daha yüksek oranda bulunmuştur. 
C. suaveolens, C. migratorius, M. guentheri, M. macedonicus ve M. tristrami türlerine İç Anadolu bölgesinde yapılan çalışmaların hepsinde rastlanması bunların bölgede yaygın olarak bulunduklarını göstermektedir. A. williamsi, M. auratus, M. brandti ve R. rattus türlerinin sadece birer çalışmada verilmesi bu türlerin daha az yoğunlukta bulunduklarına işaret etmektedir. C. cricetus türünün yalnızca [15] tarafından tespit edildiği görülmektedir. Bu türün Türkiye'de bulunduğu kuşkuludur. Dolaysıyla yanlış teşhis edilmiş olabileceği düşünülmektedir (Tablo 1).

Diğer bölgelerde yapılan çalışmalarda yoğun olarak rastlanan M. guentheri türü, Nevşehir peletlerinde daha az yoğunlukta bulunmuştur. Nevşehir civarındaki peletlerde Mus sp. oranı Diyarbakır yöresine göre daha az, A. sylvaticus oranı daha fazla bulunmuştur. C. migratorius, M. macedonicus, M. musculus, Mus sp., C. suaveolens türlerinin Nevşehir civarında az yoğunlukta görülmesi bu türlerin farklı bölgeler arasında farklı yoğunlukta dağılış gösterdikleri anlaşılmaktadır.

\section{Kaynaklar}

[1] Amr Z.S., Al-Melhim W.N., Yousef A., "Mammals remains from pellets of the Eagle owl, from Azraq Nature Reserve, Jordan” Zoology in the Middle East, 14, 5-10,1997

[2] Obuch J., "Diet of Tawny Owl (Strix aluco) in selected regions of Bohemia and Moravia" Sylvia, 30, 77-85, 1994

[3] Sommer R., Zoller H., Kock D., Böhme W., Griesau A., "Feeding of the barn owl with first record of the European free-tailed bat on the island of Ibiza (Spain, Balearics)" Folia Zoologica, 54 (4), 364-370, 2005

[4] Rubolini D., Pirovano A., Borghi S., "Influence of seasonality, temperature and rainfall on the winter diet of the long-eared owl" Folia Zoologica, 52 (1), 67-76, 2003

[5] Steiner H.M., Vauk G., "Säugetiere aus dem Beyşehir-Gebiet (Konya, Kleinasien)" Zoologischer Anzeiger, 176, 97-102, 1966

[6] Hoppe N., "Pellet contents of the Barn Owl, near Samandağ, Turkey" Zoology in the Middle East, 1, 29-31, 1986

[7] Kasparek M., "Die Sultanssümpfe. Naturgeschichte eines Vogelparadieses in Anatolien" Heidelberg, 156s, 1985

[8] Kasparek M., "Bafasee: Natur und Geschichte in der türkischgen Ägäis” Heidelberg, 174s, 1988

[9] Morgan D., “An analysis of some Eagle Owl pellets from Turkey” Sandgrouse, 5, 105-106, 1983

[10] Kock D., "Notes on mammals (Insectivora, Rodentia) taken by the Tawny Owl in NW Turkey" Zoology in the Middle East, 4, 5-9, 1990

[11] Nadachowski A, Smielowski J., Rzebikkowalska B., Daoud A., "Mammals from the Near East in Polish collection” Acta Zoologica Cracoviensia, 33(6), 91-120, 1990

[12] Seçkin S., Coşkun Y., "Mammalian remains in the pellets of the Long-eared Owls in Diyarbakır province” Turkish Journal of Zoology, 30, 271-278, 2006

[13] Hizal E., "Diet of the Long-eared Owl, Asio otus, in Central Anatolia (Aves: Strigidae)", Zoology in the Middle East, 59(2), 118-122, 2013 
[14] Bulut Ş., Akbaba B., Ayaş Z., “Analysis of Mammal Remains from Owl Pellets (Asio otus), in A Suburban Area in Beytepe, Ankara” Hacettepe Journal of Biology and Chemistry, 40 (3), 233237,2012

[15] Aşan N., Karöz A. M., Genç M., Atasoy D., Gündüz A., Akdoğan S., "Mammals in the summer diet of long-eared owl, Asio otus Linnaeus, 1758 fom Central Anatolia” 87th Annual Meeting of the German Society of Mammalogy, 2013

[16] Çolak M., "Kilis Ve Şanlıurfa İllerinden Toplanan Peletlerle, Peçeli Baykuş, Tyto alba (Scopoli, 1769) Ve Kukumav, Athene noctua (Scopoli, 1769)'nın Besin Analizi” Nigde Üniversitesi, Fen Bilimleri Enstitüsü, Biyoloji Anabilim Dall, Yüksek Lisans Tezi, 45s. Niğde, 2007

[17] Ellerman J.R., "Key to the Rodents of South West Asia" Proceedings of the Zoological Society of London, 118, 785-792, 1940

[18] Ellerman J.R., "The families and genera of living rodents" Vol. 2. Family: Muridae. British Museum Natural History London, 690s, 1941

[19] Ognev S.I., "Mammals of the USSR and adjacent countries," Vol.5, Rodents, IPST, Jerusalem, 809s, 1963

[20] Osborn D.J., "Rodents of the subfamily Microtinae from Turkey" Journal of Mammalogy, 43(4), 1962

[21] Vinogradov B.S., Argiropulo A.I., Fauna of the USSR. Mammals. "Key to rodents" Zoological Institute of the Academy of Science of the U.S.S.R. New series No: 29, IPST, Jerusalem, 241s, 1968

[22] Kryštüfek B., Vohralik V., "Mammals of Turkey and Cyprus. Order Insectivora" Knjiznica Annales Majora, 79-88, 2001

[23] Seçkin S., Coşkun Y., "Small mammals in the diet of the Long-eared Owl, Asio otus, from Diyarbakır, Turkey" Zoology in the Middle East, 35, 102-103, 2005

[24] Kahila G., Tchernov E., "Barn owls as biological pest controlls, Israel” Land \& Nature, 17(1), 68-73, 1991

[25] Seçkin S., "Güneydoğu Anadolu Bölgesi Yırtıcı Kuş Peletlerindeki Küçük Memeli Hayvan Kalıntılarının Analizi” Dicle Üniversitesi, Fen Bilimleri Enstitüsü, Doktora Tezi, 140s, Diyarbakır, 2009 